
\title{
25 Research Square \\ Union of foot/ankle Arthrodesis: A Registry Study of Low-intensity Pulsed Ultrasound (LIPUS)
}

\author{
Neil White \\ University of Calgary \\ Johnny Lau \\ University of Toronto \\ Kevin Ong ( $\nabla$ kong@exponent.com ) \\ Exponent (United States) \\ Steven Kurtz \\ Exponent (United States) \\ Sheldon Lin \\ Rutgers New Jersey Medical School
}

\section{Research Article}

Keywords: union, foot and ankle, arthrodesis, low-intensity pulsed ultrasound, LIPUS

Posted Date: January 25th, 2021

DOI: https://doi.org/10.21203/rs.3.rs-150269/v1

License: (c) (i) This work is licensed under a Creative Commons Attribution 4.0 International License. Read Full License 


\section{Abstract}

Background: Bone grafts and bone stimulation devices are used as adjuncts to foot/ankle arthrodesis to improve healing and reduce revision risk. Union rates of low-intensity pulsed ultrasound (LIPUS) and the factors associated with improved healing were evaluated.

Methods: From a prospective arthrodesis/fracture registry for EXOGEN (Bioventus LLC), treatment success for foot/ankle arthrodesis patients were was evaluated, based on both clinical (solid and painfree on manual stress) and radiological (3 of 4 cortices bridging) criteria. Associations between union rates and surgical treatments, comorbidities, and medications were tested.

Results: EXOGEN was used by a total of 235 primary and 16 revision foot/ankle arthrodesis patients. Of these, $41.4 \%$ used EXOGEN within 90 days of the fracture/arthrodesis. EXOGEN use within 90 days of the fracture/arthrodesis was associated with improved union rates (overall group ( $p=0.004$, odds ratio (OR) 3.675 (95\% Cl: 1.459-9.258)); primary group ( $p=0.007$, OR 3.383 (95\% Cl: $1.335-8.574))$ ). The overall union rate was $86.9 \%$ (primary: $86.4 \%$; revision: $93.8 \%$ ). Patients with the comorbidity of diabetes, obesity, or current smoker were not associated with a higher non-union rate $(p=0.779)$. Other comorbidities were not associated with increased non-union rates (Charcot disease $p=0.614$, NSAID $p=0.862$, steroids $p=0.647$ ). For all patients, union rates were $94.2 \%$ (EXOGEN use $\leq 90$ days post-fracture/arthrodesis) and $81.6 \%$ (>90 days).

Conclusions: Union rates for foot/ankle arthrodesis with adjunctive LIPUS were comparable to other therapies. Known patient risk factors for non-union were not found to be associated with impaired healing for the LIPUS patients, suggesting the possibility that LIPUS may mitigate these known risk factors.

\section{Introduction}

The rate of foot and ankle arthrodesis has been increasing in the United States, with national data showing a 146\% increase between 1994 and 2006 [1]. It has also been estimated that about 110,000 foot and ankle arthrodesis were performed in the United States in 2009 [2]. However, non-union after foot and ankle arthrodesis remains a clinical problem. A meta-analysis of 39 ankle arthrodesis studies with 1,262 patients reported an overall non-union rate of $10 \%$ (95\% confidence interval (Cl): $7.4-12.1 \%$ ) [3]. The incidence of non-union following foot and ankle arthrodesis can reach as high as $36 \%$ [4].To aid in healing and reduce revision risk, bone grafts and growth factors are used as adjuncts to foot/ankle arthrodesis [5]. Surgical foot/ankle arthrodesis augmented with autograft and/or allograft have yielded union rates as low as $75 \%$ [6]. Several recombinant human platelet-derived growth factor-enriched bone grafts have also been approved for use in foot and ankle applications [7], but the clinical outcomes have been mixed. One study reported union in 303 of 370 (81.9\%) of patients [8]. Other studies have reported union rates of $82.5 \%$ (33/40 patients) in patients with at least one risk factor associated with non-union, following foot and ankle arthrodesis augmented with cellular bone allograft [9]. The union rate for 
revision arthrodesis in the foot and ankle is typically lower; one study reported a 76.8\% (63/82 patients) union rate [10].

Bone stimulation devices, including low-intensity pulsed ultrasound (LIPUS) modalities, are also used as adjuncts to foot/ankle arthrodesis [5]. LIPUS appears to promote bone healing by stimulating the removal of old bone, increasing the production of new bone and increasing the rate of conversion of fibrous matrix to mineralized bone [11]. LIPUS has proven efficacy in accelerating healing after hindfoot arthrodesis [12], but the union rate achieved with LIPUS following primary or revision foot and ankle arthrodesis in a large sample of patients is poorly understood. A relatively small study of thirty patients who had delayed union of the fifth metatarsal demonstrated $90 \%$ union rate after LIPUS treatment [13]. An overall union rate was confirmed for $67 \%$ of the 18 patients after LIPUS in patients who had a number of different foot and ankle joint arthrodesis diagnosed with delayed or non-union [11]. Moreover, data on the union rate of arthrodesis with LIPUS would be useful in the context of the known risk factors for nonunion, including diabetes, tobacco use, chronic hypoxia, and vascular insufficiency, which can put patients at risk of amputation [5]. Thus, this study evaluated the union rates of LIPUS as an adjunct to foot/ankle arthrodesis and the corresponding factors associated with improved healing.

\section{Methods}

Foot/ankle arthrodesis patients were identified from a prospective arthrodesis/fracture registry for EXOGEN (Bioventus LLC, Durham, NC)[14]. EXOGEN is an FDA approved bone healing device that delivers LIPUS and is indicated for non-invasive treatment of established non-unions, excluding the skull and vertebra. EXOGEN is also indicated for accelerating the time to a healed fracture for fresh, closed posteriorly displaced distal radius fractures and fresh, closed or Grade I open tibial diaphysis fractures in skeletal mature patients that are managed by closed reduction and cast immobilization. Inclusion criteria were male patients or non-pregnant females, and 18 years of age or older at enrollment. Patients signed an informed consent at enrollment and were instructed to use the device for 20 continuous minutes every day until healed. This study was formally exempt from ethical approval by the Institutional Review Board of Duke University because data were drawn from a post-market registry meant to satisfy FDA reporting requirements [15].

Registry data for the period from 14 Oct 1994 until 15 Oct 1998 were validated by a registered nurse who manually compared every patient's paper record to the digital record. To be analyzed, each patient was required to have known date of fracture, start date of LIPUS treatment, end date of LIPUS treatment, and union outcome [14]. Treatment success in terms of union outcome was defined by both clinical (solid and pain-free on manual stress) and radiological (at least 3 of 4 cortices bridged on $x$-rays) criteria.

Data on patient age at the time of fracture, height, weight, body mass index (BMI), smoking history, intervals of time between fracture, procedure, and LIPUS treatment, gender, race, type of fracture (open/closed, closed comminuted, open grade), and comorbidities were available in the registry. The comorbidities in the data included current or past history of alcoholism, allergies, osteoarthritis, 
rheumatoid arthritis, cancer, breast cancer, cardiac disease, cardiovascular disease, Charcot disease, coronary artery disease, coronary insufficiency, diabetes, drug abuse, hypertension, Kienbock's disease, metabolic disease, myocardial infarction, neuropathy, nutritional deficiency, obesity, osteomyelitis, osteoporosis, psoriasis, renal disease, skin sensitivity, thrombophlebitis, and vascular insufficiency. The presence of having any one of diabetes, obesity, or current smoker was also examined separately. The use of medications at the time of enrollment into the registry was also collected, which included antibiotics, anticonvulsants, anticoagulants, bisphosphonates, diuretic, insulin, non-steroidal antiinflammatory drugs (NSAIDs), and steroids. The t-test was used to compare the average age and BMI for patients with and without union. The association between union rates and categorical demographics, comorbidities, and medication use was assessed with Cochran-Mantel-Haenszel statistics. CochranMantel-Haenszel statistics was also used to test the association between union rate and use of EXOGEN within or after 90 days of the fracture/arthrodesis date. All data were analyzed using SAS software, v9.4 (Cary, NC).

\section{Results}

A total of 235 primary and 16 revision foot/ankle arthrodesis patients who met the inclusion/exclusion criteria were identified in the EXOGEN registry, with $41.4 \%$ using EXOGEN within 90 days of the fracture/arthrodesis (Table 1). The average age in the overall primary and revision cohort was 50.0 years ( \pm 13.2 years), with $55 \%$ of the patients being males and $76.1 \%$ Caucasian. Obese or morbidly obese patients comprised $29.1 \%$ of the overall primary and revision foot/ankle arthrodesis cohort. About onethird $(31.5 \%)$ of the patients were previous or current smokers. Hypertension (11.2\%), diabetes (10.0\%), Charcot disease (4.8\%), vascular insufficiency (4.4\%), and rheumatoid arthritis (3.6\%) were commonly diagnosed and recorded comorbid conditions in the cohort. One of diabetes, obesity, or current smoker was present for $46.2 \%$ of the patients. No comorbid disease was indicated for $54.6 \%$ of the group. Prescription NSAIDs were used by $8.8 \%$, while non-prescription NSAIDs were used by $6.8 \%$. Analgesics and steroids were used by $10.4 \%$ and $7.2 \%$ of the patients, respectively. 
Table 1

Summary of demographics, comorbid conditions, and medication use for primary and revision foot/ankle arthrodesis patients.

\begin{tabular}{|c|c|c|c|}
\hline & $\begin{array}{l}\text { Primary } \\
(n=235)\end{array}$ & $\begin{array}{l}\text { Revision } \\
(n=16)\end{array}$ & $\begin{array}{l}\text { Overall (Primary and Revision) } \\
(\mathrm{n}=251)\end{array}$ \\
\hline $\begin{array}{l}\text { Age at fracture (years; average } \pm \text { standard } \\
\text { deviation) }\end{array}$ & $\begin{array}{l}50.2 \pm \\
13.3\end{array}$ & $\begin{array}{l}47.3 \pm \\
12.4\end{array}$ & $50.0 \pm 13.2$ \\
\hline Gender: male & $\begin{array}{l}129 \\
(54.9 \%)\end{array}$ & $\begin{array}{l}9 \\
(56.3 \%)\end{array}$ & $138(55.0 \%)$ \\
\hline Race: Caucasian & $\begin{array}{l}178 \\
(75.7 \%)\end{array}$ & $\begin{array}{l}13 \\
(81.3 \%)\end{array}$ & $191(76.1 \%)$ \\
\hline Black & $9(3.8 \%)$ & $0(0 \%)$ & $9(3.6 \%)$ \\
\hline Hispanic & $\begin{array}{l}10 \\
(4.3 \%)\end{array}$ & $1(6.3 \%)$ & $11(4.4 \%)$ \\
\hline Other & $3(1.3 \%)$ & $0(0 \%)$ & $3(1.2 \%)$ \\
\hline Unknown & $\begin{array}{l}35 \\
(14.9 \%)\end{array}$ & $\begin{array}{l}2 \\
(12.5 \%)\end{array}$ & $37(14.7 \%)$ \\
\hline $\begin{array}{l}\text { Body mass index (average } \pm \text { standard } \\
\text { deviation) }\end{array}$ & $\begin{array}{l}29.0 \pm \\
6.6\end{array}$ & $\begin{array}{l}27.9 \pm \\
6.6\end{array}$ & $29.0 \pm 6.6$ \\
\hline$<18.5$ & $3(1.3 \%)$ & $1(6.3 \%)$ & $4(1.6 \%)$ \\
\hline 18.5 to $<25$ & $\begin{array}{l}47 \\
(20.0 \%)\end{array}$ & $\begin{array}{l}6 \\
(37.5 \%)\end{array}$ & $53(21.1 \%)$ \\
\hline 25 to $<30$ & $\begin{array}{l}65 \\
(27.7 \%)\end{array}$ & $\begin{array}{l}3 \\
(18.8 \%)\end{array}$ & $68(27.1 \%)$ \\
\hline $30+$ & $\begin{array}{l}68 \\
(28.9 \%)\end{array}$ & $\begin{array}{l}5 \\
(31.3 \%)\end{array}$ & $73(29.1 \%)$ \\
\hline Unknown & $\begin{array}{l}52 \\
(22.1 \%)\end{array}$ & $1(6.3 \%)$ & $53(21.1 \%)$ \\
\hline Previous/current smokers & $\begin{array}{l}72 \\
(30.6 \%)\end{array}$ & $\begin{array}{l}7 \\
(43.8 \%)\end{array}$ & 79 (31.5\%) \\
\hline No comorbid disease reported & $\begin{array}{l}125 \\
(53.2 \%)\end{array}$ & $\begin{array}{l}13 \\
(81.3 \%)\end{array}$ & $137(54.6 \%)$ \\
\hline $\begin{array}{l}\text { One of diabetes, obesity, or current } \\
\text { smoker }\end{array}$ & $\begin{array}{l}106 \\
(45.1 \%)\end{array}$ & $\begin{array}{l}10 \\
(62.5 \%)\end{array}$ & $116(46.2 \%)$ \\
\hline Charcot disease & $\begin{array}{l}12 \\
(5.1 \%)\end{array}$ & $0(0 \%)$ & $12(4.8 \%)$ \\
\hline Diabetes & $\begin{array}{l}23 \\
(9.8 \%)\end{array}$ & $\begin{array}{l}2 \\
(12.5 \%)\end{array}$ & $25(10.0 \%)$ \\
\hline
\end{tabular}




\begin{tabular}{|c|c|c|c|}
\hline & $\begin{array}{l}\text { Primary } \\
(n=235)\end{array}$ & $\begin{array}{l}\text { Revision } \\
(n=16)\end{array}$ & $\begin{array}{l}\text { Overall (Primary and Revision) } \\
(\mathrm{n}=251)\end{array}$ \\
\hline Hypertension & $\begin{array}{l}28 \\
(11.9 \%)\end{array}$ & $1(6.3 \%)$ & $28(11.2 \%)$ \\
\hline Osteoarthritis & $5(2.1 \%)$ & $0(0 \%)$ & $5(2.0 \%)$ \\
\hline Rheumatoid arthritis & $9(3.8 \%)$ & $0(0 \%)$ & $9(3.6 \%)$ \\
\hline Renal disease & $3(1.3 \%)$ & $0(0 \%)$ & $3(1.2 \%)$ \\
\hline Vascular insufficiency & $\begin{array}{l}11 \\
(4.7 \%)\end{array}$ & $0(0 \%)$ & $11(4.4 \%)$ \\
\hline Antibiotics & $8(3.4 \%)$ & $0(0 \%)$ & $8(3.2 \%)$ \\
\hline Analgesics & $\begin{array}{l}23 \\
(9.8 \%)\end{array}$ & $\begin{array}{l}3 \\
(18.8 \%)\end{array}$ & $26(10.4 \%)$ \\
\hline Anticonvulsants & $1(0.4 \%)$ & $0(0 \%)$ & $1(0.4 \%)$ \\
\hline Anticoagulants & $6(2.6 \%)$ & $0(0 \%)$ & $6(2.4 \%)$ \\
\hline Diuretic & $7(3.0 \%)$ & $0(0 \%)$ & $7(2.8 \%)$ \\
\hline Insulin & $8(3.4 \%)$ & $1(6.3 \%)$ & $9(3.6 \%)$ \\
\hline $\begin{array}{l}\text { Prescription non-steroidal anti- } \\
\text { inflammatory drugs }\end{array}$ & $\begin{array}{l}21 \\
(8.9 \%)\end{array}$ & $1(6.3 \%)$ & $22(8.8 \%)$ \\
\hline Steroids & $\begin{array}{l}17 \\
(7.2 \%)\end{array}$ & $1(6.3 \%)$ & $18(7.2 \%)$ \\
\hline $\begin{array}{l}\text { EXOGEN use } \leq 90 \text { days post- } \\
\text { fracture/arthrodesis }\end{array}$ & $\begin{array}{l}95 \\
(40.4 \%)\end{array}$ & $\begin{array}{l}9 \\
(56.3 \%)\end{array}$ & $104(41.4 \%)$ \\
\hline
\end{tabular}

The overall union rate was $86.9 \%$, with $86.4 \%$ in the primary cohort and $93.8 \%$ in the revision cohort. For primary arthrodesis group, the mean patient age was found to be significantly lower in the union group $(49.4 \pm 13.4$ years) than non-union group $(55.2 \pm 11.8$ years; $p=0.021)$. Conversely, with only one nonunion in the revision arthrodesis cohort, the age of the non-union patient (22.0 years) was significantly lower than the union group $(48.9 \pm 10.7$ years; $p=0.029)$. In the overall group, age was not significantly different between the union and non-union groups $(p=0.051)$, although the union group tended to have younger patients (average 49.3 vs. 54.2 years). BMI was not found to be significantly different for the union and non-union groups for the primary $(p=0.499)$, revision $(p=0.074)$, or overall $(p=0.294)$ cohorts. This was still the case when BMI was stratified into underweight, normal, overweight, obese, and morbidly obese categories (primary: $p=0.735$; revision: $p=0.699$; overall: $p=0.698$ ).

Having the comorbidity of diabetes, obesity, or current smoker was not associated with a higher nonunion rate in the primary $(p=0.829)$, revision $(p=0.439)$, and overall $(p=0.779)$ cohorts (Table 2$)$. The union rate for patients having any one of those three comorbidities was $85.8 \%$ for the primary cohort, 
$90.0 \%$ for the revision cohort, and $86.2 \%$ for the overall cohort. When expanded to all the comorbidities recorded in the registry, patients having at least one comorbid disease were not found to have increased non-union rates as those with no comorbid diseases. For the primary cohort, the union rate was $83.2 \%$ for those with no comorbidities compared to $90.0 \%$ with the remaining patients $(p=0.130)$. The union rate was $92.3 \%$ for those without comorbidities in the revision cohort, compared to $100 \%$ in the group with comorbidities $(p=0.631)$. Other comorbidities and medication use were also not associated with increased non-union rates. For example, patients with Charcot disease (primary $p=0.585$; overall $p=$ 0.614 ) or vascular insufficiency (primary $p=0.655$; overall $p=0.685$ ) did not have significantly elevated non-union rates. Those using non-prescription NSAIDs (primary $p=0.893$, revision $p=0.796$, overall $p=$ 0.862 ), prescription NSAIDs (primary $p=0.216$, revision $p=0.796$, overall $p=0.212$ ), or steroids (primary $p=0.616$, revision $p=0.796$, overall $p=0.647$ ) also did not have greater non-union rates. Patients in the revision arthrodesis cohort did not have some of the comorbid conditions (for example, Charcot disease, osteoarthritis, etc.) or did not use some of the medications (for example, anticonvulsants, anticoagulants, etc.), thus comparisons could not be examined for those. EXOGEN use within 90 days of the fracture/arthrodesis date was associated with improved union rates for the overall $(p=0.004$, odds ratio (OR) 3.675 (95\% Cl: $1.459-9.258)$ ) and primary ( $p=0.007$, OR 3.383 (95\% Cl: $1.335-8.574)$ ) groups, but not the revision group $(p=0.257)$. For the overall group, union rates were $94.2 \%$ for patients who used EXOGEN within 90 days post-fracture/arthrodesis, compared to $81.6 \%$ for those who used EXOGEN after 90 days (Table 2, Fig. 1). 
Table 2

Union rate by demographic, comorbid conditions, and medication use.

\begin{tabular}{|c|c|c|c|c|}
\hline & & $\begin{array}{l}\text { Primary } \\
(n= \\
235)\end{array}$ & $\begin{array}{l}\text { Revision } \\
(n=16)\end{array}$ & $\begin{array}{l}\text { Overall (Primary and } \\
\text { Revision) }(n=251)\end{array}$ \\
\hline \multirow[t]{3}{*}{ Gender } & Female & $85.8 \%$ & $85.7 \%$ & $85.8 \%$ \\
\hline & Male & $86.8 \%$ & $100 \%$ & $87.7 \%$ \\
\hline & $p$-value & 0.829 & 0.257 & 0.668 \\
\hline \multirow[t]{6}{*}{ Race } & Caucasian & $84.8 \%$ & $92.3 \%$ & $85.3 \%$ \\
\hline & Black & $88.9 \%$ & $\mathrm{n} / \mathrm{a}$ & $88.9 \%$ \\
\hline & Hispanic & $100 \%$ & $100 \%$ & $100 \%$ \\
\hline & Other & $66.7 \%$ & $\mathrm{n} / \mathrm{a}$ & $66.7 \%$ \\
\hline & Unknown & $91.4 \%$ & $100 \%$ & $91.9 \%$ \\
\hline & $p$-value & 0.445 & 0.891 & 0.412 \\
\hline \multirow[t]{3}{*}{ Previous/current smokers } & Yes & $88.9 \%$ & $100 \%$ & $89.9 \%$ \\
\hline & No & $85.3 \%$ & $88.9 \%$ & $85.5 \%$ \\
\hline & $p$-value & 0.458 & 0.378 & 0.338 \\
\hline \multirow[t]{3}{*}{ Comorbid disease reported } & None & $83.2 \%$ & $92.3 \%$ & $83.9 \%$ \\
\hline & $\begin{array}{l}\text { At least } \\
\text { one }\end{array}$ & $90.0 \%$ & $100 \%$ & $90.4 \%$ \\
\hline & $p$-value & 0.130 & 0.631 & 0.135 \\
\hline \multirow{3}{*}{$\begin{array}{l}\text { One of diabetes, obesity, or } \\
\text { current smoker }\end{array}$} & With & $85.8 \%$ & $90.0 \%$ & $86.2 \%$ \\
\hline & Without & $86.8 \%$ & $100 \%$ & $87.4 \%$ \\
\hline & $p$-value & 0.829 & 0.439 & 0.779 \\
\hline \multirow[t]{3}{*}{ Charcot disease } & With & $91.7 \%$ & $\mathrm{n} / \mathrm{a}$ & $91.7 \%$ \\
\hline & Without & $86.1 \%$ & $93.8 \%$ & $86.6 \%$ \\
\hline & $p$-value & 0.585 & $\mathrm{n} / \mathrm{a}$ & 0.614 \\
\hline \multirow[t]{3}{*}{ Diabetes } & With & $91.3 \%$ & $100 \%$ & $92.0 \%$ \\
\hline & Without & $85.8 \%$ & $92.9 \%$ & $86.3 \%$ \\
\hline & $p$-value & 0.470 & 0.706 & 0.423 \\
\hline Hypertension & With & $88.9 \%$ & $100 \%$ & $89.3 \%$ \\
\hline
\end{tabular}




\begin{tabular}{|lllll|}
\hline & & $\begin{array}{l}\text { Primary } \\
(\mathrm{n}=\end{array}$ & $\begin{array}{l}\text { Revision } \\
\mathbf{2 3 5}\end{array}$ & $\begin{array}{l}\text { Overall (Primary and } \\
\text { Revision) }(\mathrm{n}=\mathbf{2 5 1})\end{array}$ \\
\hline \multirow{2}{*}{ Osteoarthritis } & Without & $86.1 \%$ & $93.3 \%$ & $86.5 \%$ \\
\cline { 2 - 5 } & p-value & 0.687 & 0.796 & 0.687 \\
& With & $100 \%$ & $\mathrm{n} / \mathrm{a}$ & $100 \%$ \\
\hline Wheumatoid arthritis & W-value & 0.371 & $\mathrm{n} / \mathrm{a}$ & 0.381 \\
\hline
\end{tabular}

\section{Discussion}

Our analysis of EXOGEN patients who underwent foot/ankle arthrodesis demonstrated an overall union rate of $86.9 \%$. We also found that the non-union rate was not higher in the revision cohort as those who underwent foot/ankle arthrodesis with adjunctive LIPUS had a union rate of $93.8 \%$, compared to $86.4 \%$ in the primary cohort. For the LIPUS patients, known patient risk factors for non-union, such as obesity, smoking, Charcot disease, diabetes, vascular insufficiency, NSAID use, and steroid use, were not found to be associated with impaired healing. This suggests the possibility that LIPUS may mitigate potential patient risk factors.

Our EXOGEN registry analysis demonstrated $86.4 \%$ union rate in the primary foot/ankle arthrodesis cohort and $93.8 \%$ union rate in the revision foot/ankle arthrodesis cohort. These findings were in range of other foot and ankle arthrodesis cohort studies. Teoh et al. provided thirty patients who had delayed union of the fifth metatarsal with LIPUS (EXOGEN) treatment [13] (Table 3). Twenty-seven (90\%) of the patients progressed to union clinically and radiologically. EXOGEN was used to treat 47 patients following post-traumatic and post-surgical non-unions in the foot and ankle [16]. An overall union rate of $78.7 \%$ post-LIPUS treatment was noted, but better results were observed in the tibia/ankle fracture $(92.9 \%)$ group than the midfoot/forefoot arthrodesis and fractures (77.8\%) and hindfoot arthrodesis (66.7\%) groups, however this difference was not statistically significant $(p=0.83)$. Mirza et al. also reported differences in the union rates following the use of LIPUS (EXOGEN) in patients who had a number of different foot and ankle joint arthrodesis diagnosed with delayed or non-union [11]. An overall union rate was confirmed for $67 \%$ of the 18 patients after LIPUS, but isolated small foot joints demonstrated a higher incidence of fusion ( $90 \%$; 9 of 10 patients) compared to larger or multiple joint arthrodesis (38\%; 3 of 8 patients). The healing response of tibial delayed unions was also examined in a multi-center randomized sham-controlled trial comparing subjects treated with LIPUS (EXOGEN; $n=51$ ) and those treated with an identical non-operative sham device $(n=50)$ [17]. After completion of the 16week study period, $65 \%$ of the LIPUS subjects and $46 \%$ of the sham subjects achieved healing $(p=0.07)$. The increase in bone mineral density was $34 \%$ larger among those in the LIPUS group $(p=0.002)$, while 
use of LIPUS also led to significantly smaller residual fracture gap area $(p=0.014)$. The authors concluded that there was significantly greater progress toward bone healing after LIPUS treatment. The effectiveness of LIPUS has also been shown in large registry-based EXOGEN studies to lead to successful healing in a majority of non-unions without the need for further surgical interventions [14], as well as for fresh fractures [15], but those studies included a wide range of anatomic locations and did not focus the analysis on foot and ankle arthrodesis, unlike the present study. 
Table 3

Comparative union rates for foot/ankle arthrodesis/fractures

\begin{tabular}{|c|c|c|c|}
\hline Study & Treatment & Union rate & Risk factors \\
\hline \multicolumn{4}{|l|}{ LIPUS } \\
\hline \multirow{3}{*}{$\begin{array}{l}\text { Present } \\
\text { study }\end{array}$} & \multirow{3}{*}{$\begin{array}{l}\text { Arthrodesis with adjunctive LIPUS } \\
\text { (EXOGEN) }\end{array}$} & Overall: $86.9 \%$ & \multirow[t]{3}{*}{ Extended time to LIPUS } \\
\hline & & Primary: $86.4 \%$ & \\
\hline & & Revision: $93.8 \%$ & \\
\hline \multirow{4}{*}{$\begin{array}{l}\text { Majeed } \\
2019[16]\end{array}$} & \multirow{4}{*}{$\begin{array}{l}\text { LIPUS (EXOGEN) for nonunion } \\
\text { following fracture or primary } \\
\text { surgical procedure }\end{array}$} & Overall: $78.7 \%$ & \multirow[t]{4}{*}{$\mathrm{n} / \mathrm{a}$} \\
\hline & & $\begin{array}{l}\text { Post-tibia/ankle } \\
\text { fractures: } 92.9 \%\end{array}$ & \\
\hline & & $\begin{array}{l}\text { Post-hindfoot } \\
\text { arthrodesis: } 66.7 \%\end{array}$ & \\
\hline & & $\begin{array}{l}\text { Post- } \\
\text { midfoot/forefoot } \\
\text { arthrodesis and } \\
\text { fractures: } 77.8 \%\end{array}$ & \\
\hline \multirow{3}{*}{$\begin{array}{l}\text { Mirza } \\
2019[11]\end{array}$} & \multirow{3}{*}{$\begin{array}{l}\text { LIPUS (EXOGEN) for delayed union } \\
\text { and nonunion following foot and } \\
\text { ankle arthrodesis }\end{array}$} & Overall: $67 \%$ & \multirow[t]{3}{*}{$\mathrm{n} / \mathrm{a}$} \\
\hline & & $\begin{array}{l}\text { Isolated small foot } \\
\text { joints: } 90 \%\end{array}$ & \\
\hline & & $\begin{array}{l}\text { Larger or multiple } \\
\text { joint arthrodesis: } 38 \%\end{array}$ & \\
\hline $\begin{array}{l}\text { Teoh } \\
2018 \text { [13] }\end{array}$ & $\begin{array}{l}\text { LIPUS (EXOGEN) for delayed union } \\
\text { of fifth metatarsal fracture }\end{array}$ & $90 \%$ & $\begin{array}{l}\text { Smoking, size of } \\
\text { fracture gap at } \\
\text { diagnosis of delayed } \\
\text { union }\end{array}$ \\
\hline \multicolumn{4}{|l|}{ Non-LIPUS } \\
\hline $\begin{array}{l}\text { Fragomen } \\
2012[20]\end{array}$ & Iliazarov external fixator & $83.5 \%$ & $\begin{array}{l}\text { Smoking, Charcot } \\
\text { neuroarthropathy }\end{array}$ \\
\hline \multirow{2}{*}{$\begin{array}{l}\text { Fourman } \\
2014[21]\end{array}$} & \multirow{2}{*}{$\begin{array}{l}\text { lliazarov external fixator with and } \\
\text { without recombinant human BMP- } \\
2\end{array}$} & BMP: $92.9 \%$ & \multirow[t]{2}{*}{$\mathrm{n} / \mathrm{a}$} \\
\hline & & Non-BMP: $52.5 \%$ & \\
\hline $\begin{array}{l}\text { Rogero } \\
2019[6]\end{array}$ & $\begin{array}{l}\text { IM nail with allograft (additional } \\
\text { adjunctive autograft in } 92 \% \text { ) }\end{array}$ & $75 \%$ & $\mathrm{n} / \mathrm{a}$ \\
\hline $\begin{array}{l}\text { Shah } \\
2017 \text { [19] }\end{array}$ & $\begin{array}{l}\text { Taylor spatial frame or plate and } \\
\text { screws with IM strut graft }\end{array}$ & $81.2 \%$ & $\mathrm{n} / \mathrm{a}$ \\
\hline \multirow[t]{2}{*}{$\begin{array}{l}\text { Tricot } \\
2017[18]\end{array}$} & \multirow{2}{*}{$\begin{array}{l}\text { Screw/plate with: (1) autograft and } \\
\text { DBM, or (2) allograft, DBM, and } \\
\text { BMA }\end{array}$} & $\begin{array}{l}\text { Autograft + DBM: } \\
82 \%\end{array}$ & \multirow[t]{2}{*}{ Diabetes } \\
\hline & & $\begin{array}{l}\text { Allograft + DBM + } \\
\text { BMA: } 87 \%\end{array}$ & \\
\hline
\end{tabular}


In the present study, union rates for foot/ankle arthrodesis with adjunctive LIPUS were found to be at least comparable to other therapies (Table 3). Others have reported lower union rates of $75 \%$ following IM nail use with allograft and additional adjunctive autograft [6]. Allograft has also been combined with demineralized bone matrix and iliac bone marrow aspirate during ankle and hindfoot arthrodesis with screw/plate [18]. A union rate of $87 \%$ was reported for this group of 52 patients compared to $82 \%$ in the autograft-demineralized bone matrix group of 30 patients. IM strut grafts have been used with Taylor spatial frame or plate and screws, leading to $81.2 \%$ union rate [19]. The results for llizarov external fixators with foot/ankle arthrodesis have been mixed. Fragomen et al. reported a fusion rate of 83.5\%[20], but others have reported a fusion rate of $52.5 \%$ [21]. However, surgery with adjunctive recombinant human bone morphogenic protein plus llizarov frame was able to induce healing in $92.9 \%$ of patients, but this required wearing a frame for an average of 124 days [21]. Although intraoperative adjuncts are commonly used, those can add considerable treatment cost.

The success of arthrodesis depends on several factors including patient selection and patient comorbidities. Individuals with comorbidities associated with poor surgical healing or with local healing problems are predisposed to a high rate of delayed and non-union [5, 7]. However, known risk factors for non-union were not found to be associated with healing for the LIPUS patients in the present study, which suggests the possibility that LIPUS was able to mitigate potential patient risk factors. Smoking and overweight patients have been identified as risk factors for nonunion following arthrodesis [22]. Fragomen et al. reported that- smoking was associated with a $54 \%$ rate of nonunion in their cohort of ankle arthrodesis patients treated with the llizarov method. Obesity has also been identified as a risk factor for delayed healing, based on an analysis of 9,482 metatarsal fractures in the Medicare dataset [13]. But both smoking and obesity did not appear to impair healing in the present cohort of patients treated with LIPUS (Table 2). Others have also observed no correlation between smoking status and union in a study of 18 patients who were treated with LIPUS following delayed union and non-union postfoot and ankle arthrodesis [11]. Similarly, diabetes was shown to impair healing after arthrodesis [23, 18], yet diabetes was not associated with a reduced union rate among our LIPUS patients. Majeed et al. also observed that nine of twelve diabetic patients attained union following EXOGEN treatment for symptomatic and radiological nonunion for a variety of foot and ankle pathologies [16]. In addition to comorbid diseases, previous attempted fusion is a risk factor for non-union [7]. O'Connor et al. reported a lower union rate of $77 \%$ for revision arthrodesis in the foot and ankle [10]. They also found that there was a subsequent three-fold increase in the risk of persistent non-union as the number of attempted revisions increased. In contrast, the present study showed a high union rate of $93.8 \%$, albeit in a relatively small revision arthrodesis cohort. The use of medications, such as anticonvulsants, NSAIDs, anticoagulants, antibiotics, insulin, and diuretics have been implicated as potential risk factors for fracture non-union [24]. However, potential mitigation of these risk factors was suggested in our study as their usage was not associated with increased non-union.

EXOGEN use within 90 days of the fracture/arthrodesis date was associated with improved union rates compared to use after 90 days post-fracture/arthrodesis for the overall and primary cohorts in the present study. On the other hand, a study of thirty patients who went on LIPUS treatment after delayed union of 
the fifth metatarsal showed no significant association between duration from initial injury to starting LIPUS treatment and union [13]. It is unclear if the patients in our study who initiated use of EXOGEN after 90 days may have shown indications of potential delayed or non-union for the clinician to prescribe its use. LIPUS may have been used as a last resort to achieve union before considering revision surgery. The union rate in that group of patients was still relatively high (81.6\%) despite their potential clinically disadvantaged circumstances and/or delayed use of EXOGEN.

The present study had several limitations. In addition to non-union, complications of joint fusion can include infection, wound dehiscence, failure of fixation, mal-alignment, and proximal or distal joint deterioration [25]. However, these risks were not assessed because the data was not collected as this was a post-market registry meant to satisfy FDA reporting requirements [15]. Due to the retrospective nature of this registry study, we were unable to directly examine the mechanism by which LIPUS may have mitigated the risk factors for failed arthrodesis. A recent report described an increase in blood flow of the foot in healthy volunteers exposed to LIPUS for periods as short as 20 minutes per day, suggesting that the improved microcirculation may be accelerating bone healing [26]. A small number of revision foot/ankle arthrodesis patients exists in the study, but the result was encouraging to observe that those patients did not have a clearly higher non-union rate than the primary foot/ankle arthrodesis patients. The study may also not have been able to detect differences between patients with and without certain comorbid conditions due to the somewhat limited number of patients with the comorbidities. We were also unable to ascertain the treatment compliance rates for the study cohort as this data was not collected.

In summary, the results of this study of the adjunctive use of LIPUS therapy revealed relatively high union rates and the lack of association between non-union rates and comorbidities. The findings of this study suggest that LIPUS warrants consideration as a relatively low risk post-operative adjunct. Further research should include prospective randomized trial of LIPUS with foot/ankle arthrodesis patients undergoing bone grafting with and without LIPUS.

\section{Abbreviations}

BMI: body mass index

Cl: confidence interval

LIPUS: low-intensity pulsed ultrasound

NSAIDs: non-steroidal anti-inflammatory drugs

OR: odds ratio

\section{Declarations}




\section{Ethics approval and consent to participate}

This study was formally exempt from ethical approval by the Institutional Review Board of Duke University because data were drawn from a post-market registry meant to satisfy FDA reporting requirements.

\section{Consent for publication}

Not applicable

\section{Availability of data and materials}

All data generated or analyzed during this study are included in this published article.

\section{Competing interests}

KLO: reports other from Bioventus, during the conduct of the study; other from Medtronic, other from Stryker Orthopaedics, other from Ferring Pharmaceuticals, other from Sanofi, other from Paradigm Spine, other from Pacira Pharmaceuticals, other from St. Jude Medical, other from Relievant Medsystems, other from International Society for the Advancement of Spine Surgery, other from SI-Technology, other from Zimmer-Biomet, other from Joerns Healthcare, other from SpineFrontier, other from Ethicon, other from DJO, other from Ossur, other from Rex Medical, other from Karl Storz Endoscopy-America, outside the submitted work; .

SMK: reports that he is an employee and shareholder of Exponent, Inc.; that institutional support from Bioventus was received for the submitted work; and that institutional support is received as a PI from Stryker, Zimmer Biomet, Invibio, Wright Medical Technology, Ceramtec, Celanese, Simplify Medical, Ferring Pharmaceuticals, and Lima Corporate, outside the submitted work.

SSL: has nothing to disclose.

JTL: reports other from Zimmer Biomet, other from Bioventus, other from Integra, other from Synthes, outside the submitted work; and Bioventus, Consultant and Speaker's Bureau.

NJW: reports grants from Bioventus, outside the submitted work; and Bioventus having previously funded my research (although unrelated). I have consulted for Bioventus in the past.

There are no other financial or non-financial conflict of interest.

\section{Funding}


This work was supported by Bioventus. Bioventus provided support for data extraction and statistical analysis, but provided minimal input into the design of the study and played no role in the interpretation of the data and preparation of the manuscript. Bioventus reviewed the manuscript editorially.

\section{Authors' contributions}

KLO: made substantial contributions to the design of the study, interpreted the data, and was a major contributor in drafting the manuscript

SMK: interpreted the data and was a major contributor in drafting the manuscript

SSL, JTL, NJW: interpreted the data and was a major contributor in revising the manuscript

All authors read and approved the final manuscript.

\section{Acknowledgements}

We like to acknowledge John Jones for his statistical work and Grant Steen for his contribution to the original conception of the work.

\section{References}

1. Best MJ, Buller LT, Miranda A. National Trends in Foot and Ankle Arthrodesis: 17-Year Analysis of the National Survey of Ambulatory Surgery and National Hospital Discharge Survey. The Journal of foot and ankle surgery : official publication of the American College of Foot and Ankle Surgeons. 2015;54(6):1037-41. doi:10.1053/j.jfas.2015.04.023.

2. DeVries JG, Scharer B. Comparison and Use of Allograft Bone Morphogenetic Protein Versus Other Materials in Ankle and Hindfoot Fusions. The Journal of foot and ankle surgery : official publication of the American College of Foot and Ankle Surgeons. 2018;57(4):707-11. doi:10.1053/j.jfas.2017.12.010.

3. Haddad SL, Coetzee JC, Estok R, Fahrbach K, Banel D, Nalysnyk L. Intermediate and long-term outcomes of total ankle arthroplasty and ankle arthrodesis. A systematic review of the literature. The Journal of bone and joint surgery American volume. 2007;89(9):1899-905. doi:10.2106/JBJS.F.01149.

4. Yasui Y, Hannon CP, Seow D, Kennedy JG. Ankle arthrodesis: A systematic approach and review of the literature. World journal of orthopedics. 2016;7(11):700-8. doi:10.5312/wjo.v7.i11.700.

5. Rabinovich RV, A.M. H, Rozbruch SR. Complex ankle arthrodesis: Review of the literature. World J Orthop. 2015;6(8):602-13.

6. Rogero R, Tsai J, Fuchs D, Shakked R, Raikin SM. Midterm Results of Radiographic and Functional Outcomes After Tibiotalocalcaneal Arthrodesis With Bulk Femoral Head Allograft. Foot \& ankle 
specialist. 2019:1938640019863260. doi:10.1177/1938640019863260.

7. Yeoh JC, Taylor BA. Osseous Healing in Foot and Ankle Surgery with Autograft, Allograft, and Other Orthobiologics. The Orthopedic clinics of North America. 2017;48(3):359-69. doi:10.1016/j.ocl.2017.03.009.

8. Krause F, Younger AS, Baumhauer JF, Daniels TR, Glazebrook M, Evangelista PT et al. Clinical Outcomes of Nonunions of Hindfoot and Ankle Fusions. The Journal of bone and joint surgery American volume. 2016;98(23):2006-16. doi:10.2106/JBJS.14.00872.

9. Dekker TJ, White P, Adams SB. Efficacy of a Cellular Bone Allograft for Foot and Ankle Arthrodesis and Revision Nonunion Procedures. Foot Ankle Int. 2017;38(3):277-82.

10. O'Connor KM, Johnson JE, McCormick JJ, Klein SE. Clinical and Operative Factors Related to Successful Revision Arthrodesis in the Foot and Ankle. Foot Ankle Int. 2016;37(8):809-15.

11. Mirza YH, Teoh KH, Golding D, Wong JF, Nathdwarawala Y. Is there a role for low intensity pulsed ultrasound (LIPUS) in delayed or nonunion following arthrodesis in foot and ankle surgery? Foot and ankle surgery : official journal of the European Society of Foot and Ankle Surgeons. 2019;25(6):8428. doi:10.1016/j.fas.2018.11.004.

12. Coughlin MJ, Smith BW, Traughber P. The evaluation of the healing rate of subtalar arthrodeses, part 2: the effect of low-intensity ultrasound stimulation. Foot \& ankle international / American Orthopaedic Foot and Ankle Society [and] Swiss Foot and Ankle Society. 2008;29(10):970-7. doi:10.3113/FAl.2008.0970.

13. Teoh KH, Whitham R, Wong JF, Hariharan K. The use of low-intensity pulsed ultrasound in treating delayed union of fifth metatarsal fractures. Foot. 2018;35:52-5. doi:10.1016/j.foot.2018.01.004.

14. Zura R, Della Rocca GJ, Mehta S, Harrison A, Brodie C, Jones J et al. Treatment of chronic ( $>1$ year) fracture nonunion: heal rate in a cohort of 767 patients treated with low-intensity pulsed ultrasound (LIPUS). Injury. 2015;46(10):2036-41.

15. Zura R, Mehta S, Della Rocca GJ, Jones J, Steen RG. A cohort study of 4,190 patients treated with low-intensity pulsed ultrasound (LIPUS): findings in the elderly versus all patients. BMC Musculoskelet Disord. 2015;16:45.

16. Majeed H, Karim T, Davenport J, Karski M, Smith R, Clough TM. Clinical and patient-reported outcomes following Low Intensity Pulsed Ultrasound (LIPUS, Exogen) for established post-traumatic and post-surgical nonunion in the foot and ankle. Foot and ankle surgery : official journal of the European Society of Foot and Ankle Surgeons. 2019. doi:10.1016/j.fas.2019.05.009.

17. Schofer MD, Block JE, Aigner J, Schmelz A. Improved healing response in delayed unions of the tibia with low-intensity pulsed ultrasound: results of a randomized sham-controlled trial. BMC musculoskeletal disorders. 2010;11:229. doi:10.1186/1471-2474-11-229.

18. Tricot M, Deleu PA, Detrembleur C, Leemrijse T. Clinical assessment of 115 cases of hindfoot fusion with two different types of graft: Allograft+DBM+bone marrow aspirate versus autograft+DBM. Orthopaedics \& traumatology, surgery \& research : OTSR. 2017;103(5):697-702. doi:10.1016/j.otsr.2017.03.014. 
19. Shah AB, Jones C, Elattar O, Naranje SM. Tibiotalocalcaneal Arthrodesis With Intramedullary Fibular Strut Graft With Adjuvant Hardware Fixation. The Journal of foot and ankle surgery : official publication of the American College of Foot and Ankle Surgeons. 2017;56(3):692-6. doi:10.1053/j.jfas.2017.01.055.

20. Fragomen AT, Borst E, Schachter L, Lyman S, Rozbruch SR. Complex ankle arthrodesis using the Ilizarov method yields high rate of fusion. Clin Orthop Relat Res. 2012;470(10):2864-73. doi:10.1007/s11999-012-2470-9.

21. Fourman MS, Borst EW, Bogner E, Rozbruch SR, Fragomen AT. Recombinant human BMP-2 increases the incidence and rate of healing in complex ankle arthrodesis. Clin Orthop Relat Res. 2014;472(2):732-9. doi:10.1007/s11999-013-3261-7.

22. Krause F, Younger AS, Baumhauer JF, Daniels TR, Glazebrook M, Evangelista PT et al. Clinical Outcomes of Nonunions of Hindfoot and Ankle Fusions. J Bone Joint Surg Am. 2016;98(23):200616.

23. Shibuya N, Humphers JM, Fluhman BL, Jupiter DC. Factors associated with nonunion, delayed union, and malunion in foot and ankle surgery in diabetic patients. The Journal of foot and ankle surgery : official publication of the American College of Foot and Ankle Surgeons. 2013;52(2):207-11. doi:10.1053/j.jfas.2012.11.012.

24. Zura R, Xiong Z, Einhorn T, Watson JT, Ostrum RF, Prayson MJ et al. Epidemiology of Fracture Nonunion in 18 Human Bones. JAMA surgery. 2016;151(11):e162775. doi:10.1001/jamasurg.2016.2775.

25. Martone J, Poel LV, Levy N. Complications of arthrodesis and nonunion. Clin Podiatr Med Surg. 2012;29(1):11-8.

26. Kösters AK, Ganse B, Gueorguiev B, Klos K, Modabber A, Nebelung S et al. Effects of low-intensity pulsed ultrasound on soft tissue micro-circulation in the foot. Int Orthop. 2017:s00264-017-3574-3.

\section{Figures}




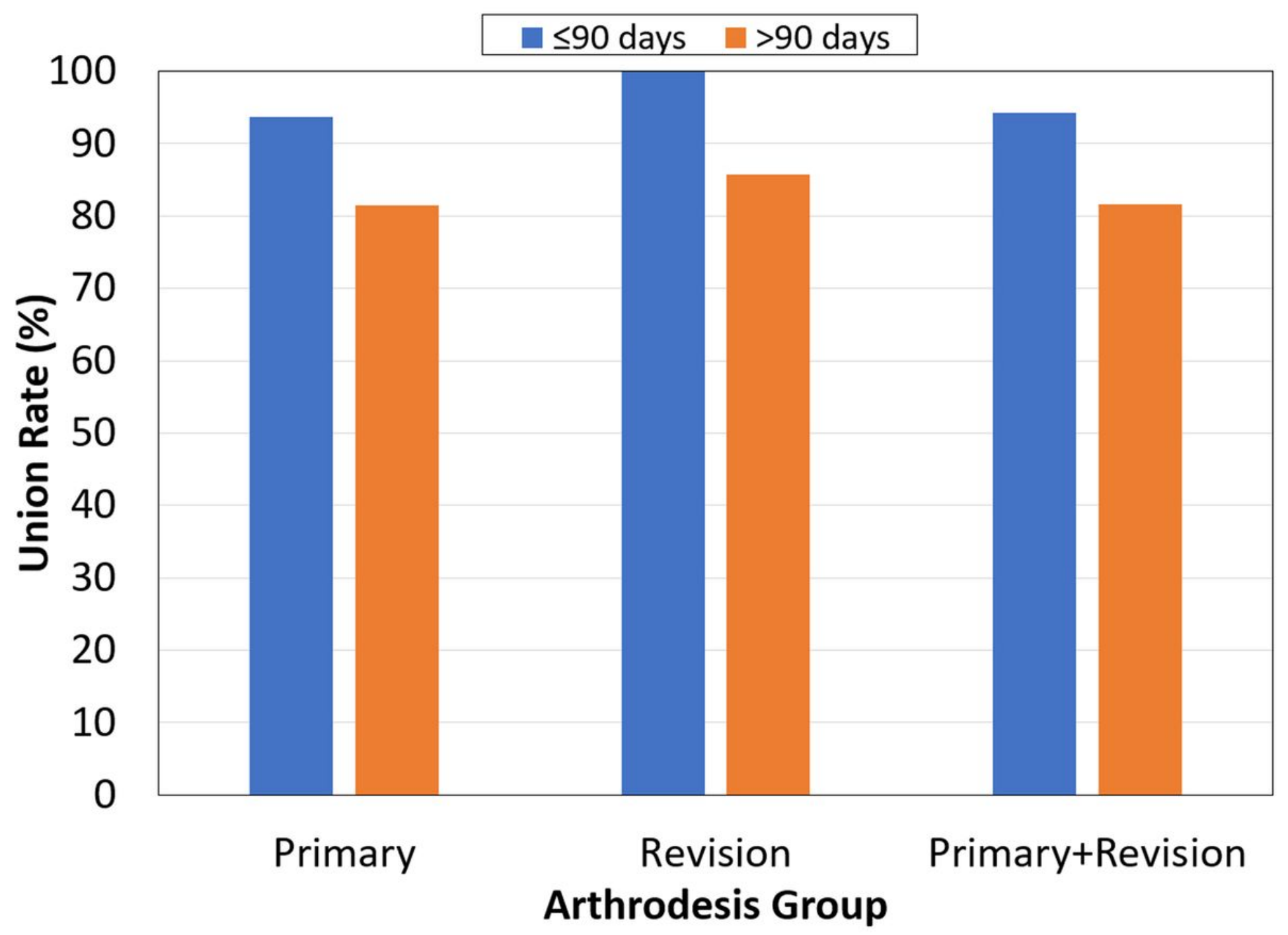

Figure 1

Union rate stratified by EXOGEN use with 90 days or after 90 days post-fracture/arthrodesis. 